Available online: https://journals.researchsynergypress.com/index.php/ijebce/

International Journal of Entrepreneurship, Business and Creative Economy (IJEBCE)

ISSN 2775-3085 (Online) | 2775-3107 (Print)

Volume 2 Number 1 (2022): 48-66

\title{
Exploring the Tagasalo Personality and Its Implication as a Localized Personality Scale
}

\author{
Arnel G. Perez ${ }^{1}$ \\ ${ }^{1}$ Institute of Arts, Sciences and Teacher Education, Mabalacat City College, Philippines
}

\begin{abstract}
Tagasalo theory hypothesized that every Filipino family has a tagasalo (catcher), a female eldest child who took household roles in early life and eventually expanded to emotional care to the members of the family. In this study, the tagasalo was explored based on the constructed personality scale, Panukat sa Tagasalo Personality (Scale for Tagasalo Personality). There were 27 participants consisting of staff, members of the faculty, field of study heads, and deans who responded to the study. The data in this study were interpreted and analyzed using t-Test: Two-Sample Assuming Unequal Variances for significant differences and regression analysis for significant correlation of the Microsoft Excel. The findings showed that the majority of the participants were Slight tagasalo. Moreover, as regards gender, the male and female participants were found to be significantly different. However, as regards ordinal position, such as firstborn child, later-born child, and others found to be no significant differences, and the majority of the participants as regards to their birth order were Slight tagasalo. In this study, the small number of samples and the use of the nonprobability sampling method may threaten the generalizability of the research findings and the representation of the entire population.
\end{abstract}

Keywords: Tagasalo; Panukat sa Tagasalo; t-Test: Two-Sample Assuming Unequal Variances; Regression analysis; Slight Tagasalo, and Generalizability

\section{INTRODUCTION}

The theory of Tagasalo as a syndrome was introduced by Carandang (1987) to describe a certain behavior of a female eldest child who acted as tagasalo (catcher). The tagasalo as mentioned by Carandang developed as early as the child took a certain role in the family, like taking care of the household, which eventually expanded to emotional care of the family members. The tagasalo's distinct character was to take care of her family, and she was driven by the compassion which took the roles and responsibilities of her parent extending to her siblings. Likewise, Carandang described the facets of tagasalo, such as the compulsive tagasalo and the non-compulsive tagasalo. The said tagasalo were both driven by compassion with different urges. The compulsive tagasalo was driven to find personal significance and external assurance, and the non-compulsive tagasalo was motivated to care and love her family and urged the need for harmony to her family. Carandang's tagasalo was very particular to sexuality and ordinal position, and this peculiarity of tagasalo stimulated the interest of the community about the origin, development, and dynamic of tagasalo. 
International Journal of Entrepreneurship, Business and Creative Economy (IJEBCE), Vol. 2 (1), 48-66 Exploring the Tagasalo Personality and Its Implication as a Localized Personality Scale

Arnel G. Perez

One of the studies about the tagasalo theory was conducted by Udarbe (2001), she investigated the origin, development, and its dynamics. In the study, she likewise cited the counterpart of tagasalo as syndrome in Western thoughts and she found a wide variety of possibilities which the term can be associated with careaholics, workaholics, busyaholics, and rushaholics. Moreover, Udarbe's study about tagasalo generated new concepts which brought confusion to the community as regard to its origin, development, and dynamics. This was evident in the previous studies in which they associated tagasalo with parentification. Atenas et al. (2018) used the term pagsalo (catch or catching), the action of the tagasalo(catcher), to describe adolescents' adaptation of adult family roles in providing emotional support for their families. Similarly, Agor, et al. (2018) associated taga-salo with parentification. The tagasalo as a syndrome (Carandang, 1987) eventually became a personality as revealed in Udarbe's study. Udarbe found that the tagasalo was not specific to eldest or middle born female child, but rather the tagasalo in the Filipino family can be either a male or female and not specific to birth order such as the eldest or the middleborn.

The tagasalo as a syndrome (Carandang, 1987) and eventually as a distinct personality of Filipino children (Udarbe, 2001) challenged the communities of the Filipinos who were affiliated in the fields of psychology. Recently, Tuazon and Quinain (2020) presented their proposed personality scale to measure the tagasalo personality during the PAP Research e-conference, and in their presentation, they stressed the tagasalo's characteristics such as being responsible, sensitive to the feelings of others, a loving child, and the capacity for caring.

In this present study, the tagasalo personality was determined through the constructed scale of Tagasalo Personality, which underscored the tagasalo as Nakatuon sa Magulang (Parent as Center) and as the Kakayahan sa Pangangalaga (Capacity for Caring). The scale for Tagasalo Personality consists of 35 items, stated in Filipino language, and its interpretation was obtained through the mean scores of the examinees or test takers. The mean scores in this study will be verbally interpreted as Ganap na Tagasalo (Absolute Tagasalo), Bahagyang Tagasalo (Slight Tagasalo), May Potensyal na maging Tagsalo (Potential Tagasalo), and Hindi Tagasalo (NonTagasalo). Moreover, this study does not limit its purpose in identifying and determining the tagasalo personality. The study likewise aimed to explore the tagasalo personality pertaining to the significant relationship of the variables such as Parent as Central and Capacity for Caring; Listener with Mediator and Harmonizer; Taking Care of the Family and Taking Care of Others; being Responsible and Loving Child/sibling; and Sensitive to the feelings of others and Concern for others. Similarly, the study will determine the differences between the responses of the male and female participants as well as their birth orders. Hence, from the correlations of the variables as well as their differences, the study will also scrutinize the implication of the Tagasalo Personality as a localized personality scale.

\section{LITERATURE REVIEW}

Prior studies and literature about the tagasalo as a syndrome as well as personality were rare and arduous to find in the online research platform. In this study, the tagasalo's origin, development, and dynamic will be elaborated based on the available resources found in the online research platform. The origin of the term, tagasalo (catcher) was introduced by Carandang (1987) to describe a certain syndrome among the female eldest or middle born Filipino children who 
International Journal of Entrepreneurship, Business and Creative Economy (IJEBCE), Vol. 2 (1), 48-66 Exploring the Tagasalo Personality and Its Implication as a Localized Personality Scale

Arnel G. Perez

developed the syndrome in taking roles like doing household chores and eventually evolved into emotional care to the members of the Filipino family. Carandang's assumption about the development of the tagasalo syndrome was confined to a particular norm found in the setting of the Filipino families. Capuno et al. (2013) mentioned that some basic elements of families in the Philippines were family- centered, child-centric, having close ties, and large family size. Similarly, Carandang's theory of tagasalo stressed that the female eldest or firstborn developed the tagasalo syndrome, and in her absence, the middle born. However, this assumption about the first and middle-born child as the tagasalo was disproved by Udarbe (2001). In the study, Udarbe found that the tagasalo was not specific to female firstborn or middle born child; she likewise discovered that even the youngest could be tagasalo, and the tagasalo was not specific to female sexuality.

Moreover, the assumption about the firstborn or middle-born child as tagasalo can be clarified with Adler's birth order theory as emphasized in the study of Coan, Garia, and Sabuncu (2018). In the study, the researchers reviewed different studies related to Adler's birth order theory (Adler, 1927), and one of the characteristics of the female eldest tagasalo that was related to the firstborn was their being adult-oriented who had the tendency to take care of their younger siblings. Similarly, the study stressed that the firstborn children were role models, and they had the habits of imitating their parents and taking on the responsibility to some degree of raising their younger siblings. This finding was related to Carandang's description of the female firstborn tagasalo who developed the syndrome in taking responsibility such as household chores which eventually expanded to emotional care to the member of the family.

The assumption that birth order influences numerous qualities of a person's life has been proven and disproved in various studies. Recent studies about birth orders were concerned with the impact of birth order on personality and leadership (Jalajas \& Tricarichi-Funk, 2018); the influence of birth order on academic success (Barclay, Hallstern \& Myrskyla, 2017), and on exploring Adler'sdolooo birth order theory (Coan, et al., 2018). These studies were some of the proofs that birth order was significant and influential to some aspects of a person's life.

In the study conducted by Jalajas \& Tricarichi-Funk (2018), they explored the relationship between birth order and personality as well as leadership. There were 59 undergraduate and graduate students who participated during the administration of the Big Five inventory (BFI) and the Multifactor Leadership Questionnaire (MLQ). In the study, the researchers employed an independent sample t-test to measure the significant differences in the means of the five personality variables between the firstborns and later-borns, and the result found no significant differences. Similarly, the result in the comparison between birth order and leadership style showed no significant differences between the firstborns and the later-borns. Hence, the study contradicted the findings in the previous study, which assumed that the firstborn could be more socially assertive and inclined toward leadership roles and likewise found that the firstborns were overrepresented in political positions (Coan, et al., 2018). Similarly, this finding refuted the idea about the female firstborn tagasalo who perceived herself as powerful (Carandang, 1987) and prime mover (Udarbe, 2001).

Barclay et al. (2017) studied the relationship between birth orders and college majors in Sweden. The data were generated using Swedish administrative register data and sibling fixed effects to address the effect of birth order on educational choices. The study found that firstborns applied and graduated from medicine and engineering programs in university, while the later- 
International Journal of Entrepreneurship, Business and Creative Economy (IJEBCE), Vol. 2 (1), 48-66 Exploring the Tagasalo Personality and Its Implication as a Localized Personality Scale

Arnel G. Perez

borns pursued journalism and business programs and attended art school, which were prevalent with families with high socioeconomic status. Similarly, the study indicated that early life experiences and parental investment had shaped sibling differences in ability, preferences, and ambitions even within the shared environment of the family. In this study, it has been proven that birth order was significant in pursuing careers. However, the study clarified that this finding was stronger in high-socioeconomic status families, and this was likewise influenced by the early life experiences and parental investment. Hence, it can be assumed that socioeconomic status, early life experiences, and parental investment impacted the siblings regardless of birth order.

In the study conducted by Coan et al.(2018), they reviewed and examined forty-five (45) articles that linked birth order, personality patterns, and habit formations. The output of the study synthesized the behaviors, personalities, and potentials of the firstborns, middleborns, lastborns, and only children. Similarly, the study found that most studies were on firstborn and lastborn children rather than middle-born children, and studies on only children were disputed as being stereotyped. Moreover, the study stressed that family dynamics and parental attention at an early age contributed to personality patterns and habit formations later in life. Hence, the study underscored that understanding birth order theory can be a useful tool to help leaders and managers better understand themselves and maximize the potential of others. In addition, Mischenko (2018) asserted that understanding birth order theory could help people in both personal and professional capacities to evaluate their strengths and weaknesses, develop their leadership styles, and build organizational cohesiveness.

As previously mentioned, birth orders were significant and influential to some aspects of a person's life. Carandang (1987) believed that tagasalo was a female eldest child and, in her absence, the middleborn child. Barclay et al. (2017) found that birth orders were significantly correlated to course preferences. Coan, et al.(2018) proved that the firstborns were adult-oriented, assertive, and inclined toward leadership roles. Mischenko (2018) affirmed that understanding birth orders could be beneficial in building organizational cohesiveness. These findings had proven the significant influences of birth orders on personality, career preferences, leadership style, and some aspects of life.

In this study, gender was one of the variables assumed to be significantly related to personality. Carandang (1987) stressed that the tagasalo was a firstborn female child who developed the syndrome during the early stage of her life. However, the study of Udarbe (2001) repudiated the theory of tagasalo syndrome and inferred that the tagasalo, regardless of what gender and ordinal position developed out of the need of the child to become different from the siblings who caused emotional upheaval in the family. Gender in this study specific to males and females presumed to be correlated to personality, specifically to tagasalo personality.

Komlenic et al. (2020) found that femininity, masculinity, and communication were significant predictors of positive attitudes towards life in both men and women. Results in this study likewise showed that both male and female participants, in general, obtained a positive attitude towards life as well as positive affectivity. Gender being a male and female showed no significant differences towards subjective well-being.

Giola and Kajonus (2019) confirmed that country's sex differences were strongly correlated with their Gender-Equality Index and as gender equality increases, both men and women tend to gravitate towards their traditional gender role. Similarly, the study found that women, to a 
International Journal of Entrepreneurship, Business and Creative Economy (IJEBCE), Vol. 2 (1), 48-66 Exploring the Tagasalo Personality and Its Implication as a Localized Personality Scale

Arnel G. Perez

greater extent, were worried, social, inquisitive, caring, and more responsible than men in more gender- equal countries. This finding to some extent favored the theory of the tagasalo syndrome (Carandang, 1987), who assumed that female eldest children were more tagasalo.

Kowalski and Scheitle (2019) mentioned that attitudes about gender roles and sexuality were frequently intertwined. The study had a sample of 5391 US adults, which was composed of heterosexual (96.25\%), gay or lesbian (1.81\%), and bisexual (1.94\%). Moreover, in the study, they found that gay men and lesbian women, when it comes to household and family roles, they were more likely than their heterosexual peers who reject traditional gender roles. The study stressed the differences between homosexual and heterosexual groups towards their attitudes to household and family roles and found that gay and lesbian individuals were more likely. However, in the tagasalo theory (Carandang, 1987), the tagasalo was confined only to genders such as male and female, and it specified that the tagasalo was the firstborn female child. On the contrary, Udarbe (2001) affirmed that the tagasalo was not specific to gender and birth order. Thus, it can be assumed even the genders with gender identities such as lesbian, gay, bisexual, transgender/transexual, and queer are likewise tagasalo.

Kulik (2018) examined the differences in egalitarianism in gender-role attitudes in Israel based on the following variables such as sex, sexual orientation, and background variables. The sample of the study consisted of 228 participants whose sexual orientations were homosexuals

(114) and heterosexuals (114). In the study, Kulik confirmed that egalitarianism in genderrole attitudes was comparable among homosexuals and heterosexuals as well as among men and women. Women's gender-role attitudes were more egalitarian than those of men. Similarly, the attitudes of homosexuals were more egalitarian than those of heterosexuals in all three domains, such as work, family, and interpersonal relations. The findings in this study stressed that women's attitudes toward gender roles were more egalitarian than men's attitudes, and in regard to sexual orientation, homosexuals' attitudes towards gender-role were more egalitarian than the heterosexuals' attitudes. As previously mentioned, the tagasalo as a syndrome (Carandang, 1987) and personality (Udarbe, 2001) was not particular with gender identities such as lesbian, gay, bisexual, transgender/transexual, and the queer. Hence, in regard to sexual orientations and gender identities, it can be presumed that they are likewise tagasalo.

Furthermore, the tagasalo as syndrome and personality embedded and developed from the Filipino family system specific to gender roles, parenting styles, and cultural norms. Carandang (1987) theorized that the female eldest child developed the tagasalo syndrome in the early stage of her life when she took the household role, which eventually evolved into emotional care to the family members. Udarbe (2001) found that the tagasalo personality developed when a member of the family took responsibility in early life. She likewise stressed that the tagasalo was moving in the opposite direction who developed out of the need to become different from a sibling who caused trouble in the family. Moreover, as mentioned by Miller and Speirs Neumeister (2017), parenting styles such as demandingness and responsiveness, authoritarian, authoritative, and permissive were found influential to the development of personality specific to being a perfectionist.

As cited by Blazevic (2016) and Miller, et al. (2017), the style of parenthood was one of the significant factors that should be observed and considered in understanding the influence of family on the social development of children. Molborn and Lawrence (2018) affirmed that family influence, household resources, social background, and parenting quality shaped healthy lifestyles 
International Journal of Entrepreneurship, Business and Creative Economy (IJEBCE), Vol. 2 (1), 48-66 Exploring the Tagasalo Personality and Its Implication as a Localized Personality Scale

Arnel G. Perez

in the early adolescent stage. Adiputra, et al. (2020) found that authoritative parenting, as well as empathy, were significantly correlated to prosocial behavior. Kosterelioglu (2018) found that democratic and overprotective parenting styles were significantly impacted the learning approach, while the authoritarian and overprotective parenting styles were significantly impacted both learning and performance-avoidance orientations. Nevertheless, Aldhafri, et al. (2020) found that the effects of parenting styles on students' self-efficacy beliefs declined as the children grew up. Parenting styles in this study were one of the variables presumed to be significantly correlated to the development of personality, particularly the tagasalo personality. However, studies such as parenting and personality, family and personality, and norms and personality were rarely conducted. Hence, future research may utilize the variables to explore their significant relationship to personality, in particular to tagasalo personality.

\section{RESEARCH METHOD}

\section{Research Design}

This study examined the nature and quality of the tagasalo personality based on the constructed tagasalo personality scale. It aimed to identify and describe the participants' responses through the degrees of the tagasalo personality scale such as Absolute Tagasalo, Slight Tagasalo, Potential Tagasalo, and the Non-Tagasalo. Similarly, the study determined the significant relationships between the exogenous and endogenous variables as well as their significant differences. Hence, in this study, the researcher utilized the correlational research method to accomplish these endeavors. In determining the degree of differences between the variables, t-Test: Two-Sample Assuming Unequal Variances was employed, and regression analysis was likewise used to determine the significant relationship between the variables (Microsoft Excel for Mac software version $16.40,2019)$.

\section{Participants}

The participants of this study were teaching-related personnel such as faculty, staff, and administrators of Mabalacat City College. There were 27 participants such as staff (6), members of the faculty (7), field of study heads (11), and deans (3) who voluntarily responded to the study. The age of the participants ranged from 22 to 52 years old, and in regard to sexuality, fourteen (14) were males, and thirteen (13) were females. As to the ordinal position (birth order) of the participants: eight (8) eldest; nine (9) middle born; seven (7) youngest; one (1) second eldest; and two (2) unintentionally missed to indicate their birth order participated during the conduct of the administration.

\section{Sampling Technique}

In this study, the sample population was determined purposively, and the participants were selected employing convenience sampling technique. As mentioned by Bengart et al. (2017), the vast majority of the studies, particularly in advertising research, relied on standard convenience sampling methods, and purposive sampling was usually employed by researchers to have more influence on the sample composition and to tailor the sample to the specific needs of the study. Likewise, these non-probability sampling techniques (purposive and convenience sampling) were employed in this study due to the grounds such as the availability of the participants (majority of 
International Journal of Entrepreneurship, Business and Creative Economy (IJEBCE), Vol. 2 (1), 48-66 Exploring the Tagasalo Personality and Its Implication as a Localized Personality Scale

Arnel G. Perez

the participants were working from home), limited period of time, and the health protocol requirements of the Inter-Agency Force or IATF (Omnibus Guidelines on the Implementation of Community Quarantine in the Philippines, 2021).

\section{FINDINGS AND DISCUSSION}

The data being generated in this study were obtained from the 27 participants who were staff, members of the faculty, field of the study heads, and deans of Mabalacat City College. The age of the participants ranged from 22 to 52 years old, and in regard to their sexuality, there were fourteen (14) males and thirteen (13) females who participated in the administration of the survey questionnaire of the Tagasalo Personality Scale. The participants' birth orders were eight (8) eldest; nine (9) middle born; seven (7) youngest; one (1) second eldest, and two (2) of the participants unintentionally missed to indicate their ordinal position. These variables were included in this study to verify the prior knowledge about the Tagasalo theory as introduced by Carandang (1987). However, in this study, the concepts about the Tagasalo focused on the personality, not on the syndrome, as first introduced by Carandang. The study about the Tagasalo Personality was conducted by Udarbe (2001), and her findings brought different concepts about the Tagasalo which the present study derived the concepts of Tagasalo Personality.

In this present study, the constructed personality scale for the Tagasalo revealed different perspectives concerning its origin, development, and dynamic, as stated in the previous studies of Carandang (1987) and Udarbe (2001). As shown in Table 1, the scale of the Tagasalo Personality was determined through the accumulated weighted mean, and each accumulated mean has an equivalent level of Tagasalo Personality (see also the Transmutation Table of Tagasalo Personality Scale). The level of the Tagasalo Personality showed that the Ganap na Tagasalo (Absolute Tagasalo) obtained a similar frequency, 2 (28.57\%) out of the 7 participants whose birth orders were eldest, middle born, and the not indicated birth order. Viz., the finding indicated that there were two (2) Absolute Tagasalo from the participants with birth order such as eldest, middle born, and the not indicated birth order. This finding repudiated the Tagasalo Theory of Carandang and affirmed the study of Udarbe.

Furthermore, the data in Table 1 revealed that there were $11(40.74 \%)$ of the participants were Bahagyang Tagasalo (Slight Tagasalo), and the data likewise showed that there were more eldest who was Slight Tagasalo, $4(36.36 \%)$ out of the 11 participants and the middle born 4 (66.67\%) out of the 6 participants, were dominant as May Potensyal na maging Tagasalo (Potential Tagasalo). This finding supported the concept of Caradang (1987), who claimed that the Tagasalo were well suited to the middle-born child in the absence of the eldest child. However, in this study, the eldest children were only dominant as Slight Tagasalo but not the Absolute Tagasalo, and similarly, the middle-born children were only distinct as Potential Tagasalo but not as Absolute Tagasalo.

Table 1. Frequency, percentage, and weighted mean on the level of Tagasalo Personality $(\mathrm{N}=27)$

\begin{tabular}{|c|c|c|c|c|c|c|c|}
\hline \multirow{2}{*}{$\begin{array}{l}\text { Level of Tagasalo } \\
\text { Personality }\end{array}$} & \multicolumn{5}{|c|}{ Frequency (f) } & \multirow[t]{2}{*}{$(\%)$} & \multirow[t]{2}{*}{ (?) } \\
\hline & $\mathrm{E}$ & $\mathrm{M}$ & $Y$ & $\mathrm{NI}$ & $\sum$ & & \\
\hline Absolute Tagasalo & 2 & 2 & 1 & 2 & 7 & 25.92 & 3.66 \\
\hline Slight Tagasalo & 4 & 3 & 3 & 1 & 11 & 40.74 & 3.21 \\
\hline Potential Tagasalo & 0 & 4 & 2 & 0 & 6 & 22.22 & 2.86 \\
\hline
\end{tabular}


International Journal of Entrepreneurship, Business and Creative Economy (IJEBCE), Vol. 2 (1), 48-66 Exploring the Tagasalo Personality and Its Implication as a Localized Personality Scale

Arnel G. Perez

\begin{tabular}{llllllll} 
None Tagasalo & 2 & 0 & 1 & 0 & 3 & 11.11 & 2.25 \\
\hline
\end{tabular}

Note. E (eldest); M (middle born); Y (youngest); and NI (not indicated birth order)

In the Table 2 of this study, the exogenous variable (IV), Nakatuon sa Magulang (Parent as Central) was correlated to the endogenous variable (DV), Kakayahan sa Pangangalaga (Capacity for Caring). The regression analysis revealed at 95\% confidence level, the obtained p-value of the Parent as Central was 0.0000 (1.189490E-08), which was less than 0.05 as the significant threshold level. This revealed that the Parent as Central was positively correlated (see the coefficient value) to the Capacity for Caring, and the variables were statistically significant. This finding likewise indicated if the responses in the items of Parents as Central were high, the responses on the items of the Capacity for Caring were likewise high. This finding assumed that if the responses in the Parent as Central are high, the responses in the Capacity for Caring are similarly high. Hence, high responses in the Parent as Central means high responses in the Capacity for Caring. Viz., the Parent as Central predicts the Capacity for Caring. Thus, the Tagasalo Personality for the Nakatuon sa Magulang (Parent as Central) with its sub-constructs such as Taga-pakinig (Listener), Tagapamagitan (Mediator), and Taga-paisuwato (Harmonizer) may influence the behaviors of the Tagasalo as the Capacity for Caring. This finding affirmed the theory of tagasalo (Carandang, 1987) and the tagasalo personality (Udarbe, 2001).

Moreover, as shown in Table 2, the obtained coefficient value of the Intercept (Alpha) was 1.3525 with a p-value of 0.0000 (3.06406E-06), which is less than 0.05 as the level of significance indicating statistically significant. This finding likewise assumed that if the mean in the Parent as Central is zero (0), then the mean for the Capacity for Caring will be at 1.3525. In regard to the pvalue of the significance $\mathrm{F}$, which is 0.0000 (1.189490E-08) less than 0.05 of the significant level, this indicated at $95 \%$ level of confidence the linear model was statistically significant. The obtained R-Square in this data was 0.73 (73\%), and it implied a low stochastic disturbance term (17\%), which indicated that the exogenous variables were sufficient enough to explain the endogenous variables.

Table 2. Regression analysis of Tagasalo for Parent as Central and Capacity for Caring ( $\mathrm{N}=27$ )

\begin{tabular}{lllll}
\hline & Coefficients & Standard Error & t Stat & P-value \\
\hline Intercept & 1.3525 & 0.2263 & 5.9761 & $3.06406 \mathrm{E}-06$ \\
Parent as Central & 0.6073 & 0.0732 & 8.3013 & $1.189490 \mathrm{E}-08$ \\
\hline
\end{tabular}

Note. Significant Level (0.05); Significance F (1.18949E-08); and R-Square (0.73)

In Table 3, under the construct Nakatuon sa Magulang (Parent as Central) such as Tagapakinig (Listener), Taga-pamagitan (Mediator), and Taga-paisuwato (Harmonizer) were correlated to find their significant relationship. As reflected in the p-value of Mediator, which was 0.034449 and less than 0.05 as the level of significance, and a coefficient value of 0.3043 showing positive correlation. This indicated that the exogenous variable, the mediator, was significantly correlated to the endogenous variable, the listener. This statistically significant relationship of the variables revealed that as the responses in the mediator were high, the responses in the listener were likewise high. Viz., the exogenous variable, mediator influenced the endogenous variable, listener. However, the other exogenous variable, harmonizer, showed no statistically significant with the endogenous variable, the listener. Even these variables were positively correlated, but the obtained 
International Journal of Entrepreneurship, Business and Creative Economy (IJEBCE), Vol. 2 (1), 48-66 Exploring the Tagasalo Personality and Its Implication as a Localized Personality Scale

Arnel G. Perez

p-value of the harmonizer was greater than 0.05 as the level of significance; this may be indicated statistically insignificant. Viz., the tagasalo as hamonizer does not influence the tagasalo as listener.

Moreover, the obtained coefficient value of the Intercept (Alpha) was 1.4513, and this may be indicated that starting mean score of the endogenous variable, the listener was 1.4513 if the mean score of the exogenous variables were zero (0). This assumption was statistically significant because the obtained p-value of the intercept was 0.001188 , which was less than 0.05 as the level of significance. This is likewise affirmed by the obtained p-value of the significance $F$, which was 0.0000 (4.067E-05), indicating that the linear model was statistically significant. In regard to the sufficiency of the exogenous variables, the obtained value of the R square was 0.57 (57\%). This indicated that the stochastic disturbance term was 0.43 (43\%).

Table 3. Regression analysis of Tagasalo as Listener, Mediator, and Harmonizer (N = 27)

\begin{tabular}{lllll}
\hline & Coefficients & Standard Error & t Stat & P-value \\
\hline Intercept & 1.4513 & 0.3947 & 3.6765 & 0.001188 \\
Mediator & 0.3043 & 0.1357 & 2.2422 & 0.034449 \\
Harmonizer & 0.3336 & 0.1871 & 1.7827 & 0.087287 \\
\hline
\end{tabular}

Note. Significant Level (0.05); Significance F (4.067E-05); and R-Square (0.57)

In Table 4, the relationship of the variables such as Pangangalaga sa Pamilya (Taking Care of the Family) and Pangangalaga sa Iba (Taking Care of Others) revealed a positive correlation and statistically significant. This was reflected on the obtained p-value of Taking Care of the Family, which was 0.00203513 less than 0.05 as the level of significance. This indicated as the mean score in the Taking Care of the Family was high, the mean score in the Taking Care of Others was likewise high. Viz., the exogenous variable, Taking Care of the Family predicts the endogenous variable, Taking Care of Others. This likewise assumed that the tagasalo who took care of his/her family also took care of his/her friends and even his/her co-workers. This finding affirmed the theory of tagasalo (Carandang, 1987) and the tagasalo personality (Udarbe, 2001), who both describe the tagasalo as being responsible and caring.

As shown in Table 4, the coefficient value of the intercept was 2.2824 . This indicated that the starting mean score for the Taking Care of Others was 2.2824 if the Taking care of the Family was zero (0). This assumption was realistic because the obtained p-value (9.8104E-08) for the intercept was less than 0.05 as the level of significance, which means statistically significant. This is likewise affirmed by the linear model, which obtained a significance $F$ of 0.00203513 less than 0.05 . However, in regard to the sufficiency of the exogenous variables, the R Square obtained was $0.32(32 \%)$, which indicated that the stochastic disturbance term was $0.68(68 \%)$.

Table 4. Regression analysis of Tagasalo for Taking Care of the Family and Taking Care of Others

$$
(\mathrm{N}=27)
$$

\begin{tabular}{lllll}
\hline & Coefficients & Standard Error & $\mathrm{t}$ Stat & P-value \\
\hline Intercept & 2.2824 & 0.3091 & 7.3838 & $9.8104 \mathrm{E}-08$ \\
Taking Care of the Family & 0.3411 & 0.0991 & 3.4432 & 0.00203513 \\
\hline
\end{tabular}

Note. Significant Level (0.05); Significance F (0.00203513); and R-Square (0.32) 
International Journal of Entrepreneurship, Business and Creative Economy (IJEBCE), Vol. 2 (1), 48-66 Exploring the Tagasalo Personality and Its Implication as a Localized Personality Scale

Arnel G. Perez

In regard to the significant relationship between Responsible and Loving child/sibling, the obtained coefficient value for an exogenous variable, Responsible, was 0.4261 , indicating positive correlation, and the obtained p-value was 0.0000 (5.50095E-06), which was less than 0.05 as the level of statistically significant indication. This finding revealed that the tagasalo as being responsible predicts his/her character as being a loving child/sibling. Likewise, this assumed if the mean score in the variable, Responsible was high, the mean score in the variable, Loving child/sibling was high too. Moreover, if the mean for Responsible was zero (0), the starting means for Loving child/sibling will be 1.9891, the coefficient value of the intercept. This assumption was realistic because the obtained p-value was 0.0000 (3.08742E-09), which was less than to 0.05 significant level. Concerning the linear model, the obtained significance F was 0.000 (5.50095E-06) less than the significant level (0.05), indicating statistically significant. The obtained R-square was 0.57 (57\%); this indicated that the stochastic disturbance term was 0.43 (43\%). This would mean that the exogenous variable, Responsible was moderately sufficient to explain the endogenous variable, Loving child/sibling.

Table 5. Regression analysis of Tagasalo as Responsible and Loving Child/Sibling ( $\mathrm{N}=27)$

\begin{tabular}{lllll}
\hline & Coefficients & Standard Error & t Stat & P-value \\
\hline Intercept & 1.9891 & 0.2231 & 8.9149 & $3.08742 \mathrm{E}-09$ \\
Responsible & 0.4261 & 0.0742 & 5.7451 & $5.50095 \mathrm{E}-06$ \\
\hline
\end{tabular}

Note. Significant Level (0.05); Significance F (5.50095E-06); and R-Square (0.57)

In Table 6, the tagasalo's character for concern for others was correlated to the character, sensitive to the feelings of others, and the finding revealed a positive correlation and statistically significant. The coefficient value for the Concern for others was 0.5033 , indicating a positive correlation, and obtained a p-value of 0.00092812 , which was less than 0.05 as the level of significance indicating statistically significant. This assumed if the mean score for the Concern for others was high, the mean score for Sensitive to the feelings of others was likewise high. Viz., the tagasalo for concern for others predicts the tagasalo's character for being sensitive to the feelings of others.

Moreover, if the mean score for Concern for others was zero (0), then the mean score for Sensitive to the feelings of others would be 1.6037. This assumption was statistically significant because the obtained p-value of the intercept (0.00163134) was less than 0.05 as the level of significance. Viz., this showed that the mean score for the variable starts at 1.6037 . The linear model was affirmed to be statistically significant; the obtained significance F was 0.0000 (1.18949E-08), which was less than 0.05 as the level of significance. The obtained R-square was $0.73(73 \%)$, indicating that the exogenous variable, Concern for others, was sufficient to explain the endogenous variable, Sensitive to the feelings of others. This likewise revealed that the stochastic disturbance term was 0.27 (27\%).

Table 6. Regression analysis of Tagasalo for Concern for others and Sensitive to the feelings of others $(\mathrm{N}=27)$

\begin{tabular}{lllll}
\hline & Coefficients & Standard Error & t Stat & P-value \\
\hline Intercept & 1.6037 & 0.4541 & 3.5314 & 0.00163134
\end{tabular}


International Journal of Entrepreneurship, Business and Creative Economy (IJEBCE), Vol. 2 (1), 48-66 Exploring the Tagasalo Personality and Its Implication as a Localized Personality Scale

Arnel G. Perez

\begin{tabular}{lrrrr} 
Concern for Others & 0.5033 & 0.1340 & 3.7544 & 0.00092812 \\
\hline
\end{tabular}

Note. Significant Level (0.05); Significance F (1.18949E-08); and R-Square (0.73)

In the theory of tagasalo as a syndrome, Carandang (1987) mentioned that every Filipino family had a tagasalo, and the tagasalo was usually the eldest female child and, in her absence, the female middleborn child. However, this assumption was contradicted by the study of Udarbe (2001) about tagasalo personality. In the study, she discovered that the tagasalo was not confined to the female eldest daughter, and she stressed that even the youngest could be tagasalo. Tagasalo was not confined to female sexuality and to the firstborn children. Moreover, as revealed in this study, the mean score of the male (2.975) and female (3.3164) participants was significantly different. The accumulated p-value (0.0465) from the t-test of two samples assuming unequal variances was less than 0.05 as the level of significance. This assumed that the mean scores between the male and female participants were significantly different. Likewise, the obtained t-stat (2.0947) was greater than the critical t-value indicating significant differences and rejecting the null hypothesis. Hence, this study found that the female participants had different responses as compared to the male responses. The finding affirmed the theory of the tagasalo of Carandang about the female firstborn child and, in her absence, the middle-born child. As revealed, the thirteen (13) female participants were a firstborn child (8) and a middle-born child (5), which exactly suited the tagasalo theory of Carandang. On the other hand, Udarbe's tagasalo personality not particular to sexuality and birth order was likewise affirmed in this study.

Table 7. Mean differences between the male and female participants $(\mathrm{N}=27)$

\begin{tabular}{lllllll}
\hline Sexuality & Mean & $\mathrm{df}$ & \multicolumn{2}{c}{$\mathrm{t}$-Value } & \\
\cline { 5 - 6 } & & & $\mathrm{t}$ Stat & $\mathrm{t}$ Critical tv & $\begin{array}{l}\mathrm{P}(\mathrm{T}<=\mathrm{t}) \\
\text { tail }\end{array}$ & two- \\
\hline Male & 2.9775 & 25 & $-2.0947^{*}$ & 2.0595 & $0.0465^{*}$ \\
\hline Female & 3.3164 & & & & \\
\hline
\end{tabular}

Note. Significant Level (0.05)

As revealed in Table 8, the birth order such as firstborn (eldest), later-born (youngest), and the other birth order (middleborn \& others) showed no significant differences in this study. The obtained means: eldest (3.0607), youngest (3.0244), and other birth orders (3.2619) were almost homogenous, indicating no significant differences. The obtained p-value between the eldest and youngest was 0.8963 , which was greater than 0.05 as the significant level affirmed no significant differences. Similarly, the obtained p-value between the eldest and the other birth orders was 0.4108 greater than 0.05 as the significant level indicating no significant difference. Moreover, the obtained $t$ stats were less than the obtained critical-t value, which implied no significant differences, which likewise indicated the acceptance of the null hypothesis. As mentioned by Udarbe (2001), the tagasalo was not confined to the female eldest child, and she affirmed that the tagasalo was notparticular to gender and to birth orders. Hence, this concept about the tagasalo was affirmed in this study that the tagasalo can be a male or female regardless of what birth orders. 
International Journal of Entrepreneurship, Business and Creative Economy (IJEBCE), Vol. 2 (1), 48-66

Exploring the Tagasalo Personality and Its Implication as a Localized Personality Scale

Arnel G. Perez

Table 8. Mean differences among the eldest, youngest, and other birth orders $(\mathrm{N}=27)$

\begin{tabular}{llllll}
\hline \multirow{2}{*}{ Ordinal Position } & Mean & df & t-Value & & \\
\cline { 4 - 6 } & & & t Stat & t Critical tv & P(T<=t) two-tail \\
\hline $\begin{array}{l}\text { Eldest } \\
\text { Youngest }\end{array}$ & 3.0607 & 13 & 0.1329 & 2.1604 & 0.8963 \\
\hline $\begin{array}{l}\text { Other Birth } \\
\text { Orders }\end{array}$ & 3.0244 & 10 & -0.8583 & 2.2281 & 0.4108 \\
\hline
\end{tabular}

Note. Significant Level (0.05)

The results in this study, to a certain extent, affirmed and disproved the theory of tagasalo (Carandang, 1987). In this study, the tagasalo personality was classified as Absolute tagasalo, Slight tagasalo, and Potential tagasalo, and the majority of the participants were Slight tagasalo. The tagasalo's personality pertained to Parent as Central and Capacity for Caring were found to be significantly correlated. Similarly, variables such as Mediator and Listener; Taking Care of the Family and Taking Care for Others; being Responsible and Loving Child/Sibling; Concern for Others and Sensitive to the Feelings of Others were found significantly correlated. Moreover, the responses between the male and female participants were found to be significantly different, and the female participants were more of Slight tagasalo while the male participants were more of Potential tagasalo. However, in regard to ordinal position, such as firstborn child, later born child, and others found to be no significant differences, and the majority of the participants in regard to their birth order were Slight tagasalo. The findings in this study were more associated with the tagasalo personality introduced by Udarbe (2001).

\section{Discussion}

Carandang (1987) assumed that the tagasalo was common to every Filipino family. She stressed that the tagasalo was a female firstborn child or a female middle born child who developed the symptoms when she took the roles like taking care of the household, which evolved into emotional care to the members of the family. The assumption of the tagasalo being the eldest child or firstborn not particular to gender and sexuality had been proven by Udarbe (2001), and she likewise mentioned that even the later-born or youngest could be tagasalo. Adler (1927, p.152-153) mentioned that historically the oldest son had a particularly favorable position. He had the advantage of an excellent position for the development of his psychic life, and usually, he was accredited with enough power and common sense to be the helper or foreman of his parent and eventually the head of the house. Coan et al.(2018) synthesized that the firstborn children were adult-oriented and role models who had a habit of imitating their parents and taking on the responsibility to some degree of raising their younger siblings. This affirmed the theory of tagasalo that the female eldest child took the responsibility such as household chores and eventually expanded to emotional care to the family members. However, the study found that the tagasalo personality was not restricted to the firstborn and middleborn child; rather, the tagasalo personality was also found to the youngest child and to the other birth orders, which were not specific to sexuality. Similarly, the study found that the majority of the participants were Slight tagasalo, and only a few of them were considered Absolute tagasalo. This Absolute tagasalo was $25.92 \%$ of the sample with different birth orders, and $57.14 \%$ were female. This finding seemed to favor the theory of tagasalo as being a female firstborn or middle-born child. 
International Journal of Entrepreneurship, Business and Creative Economy (IJEBCE), Vol. 2 (1), 48-66 Exploring the Tagasalo Personality and Its Implication as a Localized Personality Scale

Arnel G. Perez

In this study, the tagasalo personality such as Parent as Central was correlated to Capacity for Caring, and these variables were found to be correlated and statistically significant. The Parent as Central referred to the personality of the tagasalo, such as being listener, mediator, and harmonizer. These concepts were adapted to the previous study of Udarbe (2001), who clarified that certain individuals were called upon to be the tagasalo because they had relatively open communication lines with their parents. In regard to open line communication, Coan, et al.(2018) mentioned that mostly, the firstborn children were privileged to interact with adults and their parents spent more time with them, especially to activities such as playing and reading. Hence, the tendency to become tagasalo was most likely to occur with the firstborn children.

Moreover, the tagasalo personality, such as the Capacity for Caring was, referred to the aspects of life such as taking care of the family and taking care of others. Udarbe (2001) confirmed that tagasalo's capacity for caring required further elaboration because this character of tagasalo was not only directed towards the parents but to others as well. Tagasalo's capacity for caring can be attributed to the habit formation of firstborn children. Coan et al.(2018) affirmed that the firstborn children were adult-oriented, and being adult-oriented, they have the tendency to take care of their younger siblings. Furthermore, the capacity for caring was represented by tagasalo's characteristics such as being responsible, loving child/sibling, being sensitive to the feelings of others, and concerning for others. In this study, it was found out that the tagasalo for the parent as central was significantly correlated to the capacity for caring. This clarified that the tagasalo personality, particularly in this study, was consistent with his/her behavior. Being a parent as the center would likewise mean taking care of the family and taking care of others.

The variables such as listener and mediator were found to be statistically significant and correlated. The tagasalo as listener implied submission, conformity, and obedience to the parent, while the tagasalo as mediator would mean an individual who sacrificed to resolve conflict in the family. An individual who mediated and settled the conflicts in the household. Hence, the tagasalo as a listener would likewise mean mediator. Udarbe (2001) found that tagasalo has the ability to listen, who has open communication with parents, and who does not talk back or hold a grudge. Similarly, she mentioned that the tagasalo's role was to mediate between siblings to spare the parent from the stressful and burning-out roles.

Being responsible and being a loving child/sibling were some of the personalities of the tagasalo. In this study, the variables were found to be statistically significant and correlated. Being responsible would mean to surrogate the mother in her absence, like doing household chores, rearing, and taking care of the members of the family. Being a loving child/sibling would mean frequently taking care of the members of the family. The relationship of these variables indicated that the tagasalo who is responsible likewise assumes the tagasalo as a loving child/sibling. Moreover, variables such as being sensitive to the feelings of others and concern for others were likewise found to be statistically significant and correlated. This indicated that the tagasalo shows compassion and sensitivity to the feelings of others, which likewise shows concern for others. This particular personality was reflected when the tagasalo participated in volunteering activities such as helping the needy or indigent.

As regard genders, such as male and female, the tagasalo personality was both identified. Udarbe (2001) confirmed that the tagasalo was not specific to the female eldest child and, in her absence, the middle-born child. Giola and Kajinus (2019) affirmed that both men and women tend 
International Journal of Entrepreneurship, Business and Creative Economy (IJEBCE), Vol. 2 (1), 48-66 Exploring the Tagasalo Personality and Its Implication as a Localized Personality Scale

Arnel G. Perez

to gravitate toward their traditional gender roles as gender equality increases. However, the finding showed significant differences between the male and female participants, which likewise coincided that the female participants' birth orders were firstborns and middleborns. This unexpected result, to a certain extent, favored the theory of tagasalo (Carandang, 1987), which assumed that the tagasalo was a female eldest or middle born child. In addition, this would assume that the tagasalo is probable to female eldest or female middle born child.

In this study, the birth order variables such as firstborn, later born, and the not indicated birth order found no significant differences. This would assume that any member of the Filipino family can be a tagasalo regardless of what ordinal position or birth order. However, as previously mentioned, the probability of becoming tagasalo could be the firstborn or middle-born child. Likewise, previous studies, as reviewed by Coan, et al. (2018), revealed that the firstborns were adult-oriented and tended to take care of their younger siblings. On the contrary, the middle-born children were friendship specialists who formed stronger bonds with their friends rather than their family.

\section{The implication of the Tagasalo Personality Scale as a Localized Personality Scale}

As shown in the findings of the study, the Panukat sa Tagasalo Personality (Tagasalo Personality Scale) revealed that the tagasalo was not particular to gender and birth order. However, the study found significant differences in the mean scores between the male and female participants. The female participants, in regard to their ordinal position, were firstborn and middleborn children. This finding, to certain extent, affirmed the tagasalo's theory (Carandang, 1987) and the personality of the firstborns in Adler's birth order theory (Coen, et al., 2018).

Moreover, the tagasalo in this personality scale described the tagasalo for being the Parent as Central and the Capacity for Caring. In Parent as Central, the scale assessed the tagasalo with the following criterion's such listener (taga-pakinig), mediator (taga-pamagitan), and harmonizer (taga-paisuwato). The criterion for the listener determines the personality of the tagasalo as an individual who is submissive, conformist, and obedient to his/her parent, who likewise understands and listens to his parent as well as his/her siblings. Udarbe (2001) stressed that the tagasalo has the ability to listen who does not talk back or hold a grudge.

As a mediator, this criterion determines the personality of the tagasalo as an individual who is willing to sacrifice to resolve conflict in the family. A member of the family who mediated and settled the conflict between mother and father, mother and child, father and child, and sibling and sibling. Udarbe (2001) mentioned that the tagasalo's role was to mediate between siblings to spare the parent from the stressful and burning-out situation.

As harmonizer, this criterion determines the tagasalo's personality as an individual who immediately responds and takes action to maintain harmony at home. An individual who promptly wishes for orderliness and tranquility when the members of the family are in a difficult situation or when they are in the worst situation. Similarly, the harmonizer is an individual who experiences restlessness and confusion when there is conflict and misunderstanding among the members of the family. Udarbe (2001) explained that the tagasalo was a fixer who wanted to resolve matters quickly and took the responsibility to fix the conflict in the family.

The Capacity for Caring in the tagasalo personality scale measures the tagasalo's capacity to take care of the family (Pangangalaga sa Pamilya) and to take care of others (Pangangalaga sa 
International Journal of Entrepreneurship, Business and Creative Economy (IJEBCE), Vol. 2 (1), 48-66 Exploring the Tagasalo Personality and Its Implication as a Localized Personality Scale

Arnel G. Perez

Iba). In Taking Care of the Family, this criterion is determined through the criteria, Responsible (Mananagot) and Loving Child/Sibling (Mapagkalingang Anak/Kapatid). The criterion, Responsible, determines the tagasalo's personality as an individual who surrogates the mother in her absence and takes the responsibility as the head of the family. Similarly, this criterion describes the tagasalo as an individual who helps the mother in doing household chores. Being responsible as one of the personalities of tagasalo is associated with the mother's responsibilities such as doing household chores, rearing, and taking care of the children. Carandang (1987) hypothesized that the female eldest child developed the tagasalo syndrome when she took responsibility, such as household roles, and eventually expanded to emotional care to the members of the family. Similarly, Udarbe (2001) identified that tagasalo is an individual who took responsibility early in life.

Tagasalo's capacity for taking care of the family is likewise determined through the criterion, Loving Child/Sibling. This criterion determines the tagasalo's personality as an individual who frequently take care of the members of the family and who feels restless if a family member gets sick. Similarly, this criterion determines the tagasalo based on his/her attitude towards the health and welfare of the family. Udarbe (2001) found out that generosity, approachability, and thoughtfulness were the indicators of the tagasalo's capacity for caring, and as a sibling, she described the tagasalo as an individual who was moving in the opposite direction.

In Taking Care of Others, this criterion is determined through the criterions such as Sensitive to the feelings of others (May-pakiramdam sa saloobing ng iba) and Concern for others (May- malasakit sa iba). The criterion, Sensitive to the feelings of others, describes the tagasalo as an individual who has compassion and a sense of sensitivity. Moreover, this criterion likewise describes the personality of the tagasalo who does not compete and considers others' feelings, particularly in decision making and in implementing action. The criterion, Concern for others, describes the tagasalo who finds joy in helping others and in volunteering to activities that concern the welfare and health of others.

In this study, the Panukat sa Tagsalo Personality was not correlated with other personality scales or assessments. As observed, the Panukat sa Tagasalo Personality has potential in assessing personality. It can be correlated to Adlerian Personality Priority Assessment (APPA), NEO Personality Inventory-Revised (NEO PI-R),16 Personality Facets (16PF), Minnesota Multiphasic Personality Inventory (MMPI), Millon Clinical Multiaxial Inventory (MCMI), California Psychological Inventory (CPI) and other personality assessments.

\section{CONCLUSION \& FURTHER RESEARCH}

The results in this study, to a certain extent, affirmed and disproved the theory of tagasalo (Carandang, 1987) and the tagasalo personality (Udarbe, 2001). The Panukat sa Tagasalo Personality (Scale for Tagasalo Personality) revealed that the tagasalo is an individual who accepts that the parent as central. The tagasalo, as one of his/her personalities, spared the parent from stress and burning-out situations by immediately taking the responsibilities. The tagasalo is equipped with skills such as listening, meditating, and harmonizing. The tagasalo is an individual who has a strong concern for his/her family and to others. The tagasalo as a loving child/sibling, extends his/her emotional care to others.

In this study, the Panukat sa Tagasalo Personality depicted that variables are statistically significant and correlated. That the male and female tagasalo are significantly different, and the firstborn birth order is not an indicator of tagasalo but has a strong probability of becoming tagasalo. The tagasalo in this study is described as being Absolute Tagasalo, Slight Tagasalo, and 
International Journal of Entrepreneurship, Business and Creative Economy (IJEBCE), Vol. 2 (1), 48-66 Exploring the Tagasalo Personality and Its Implication as a Localized Personality Scale

Arnel G. Perez

Potential Tagasalo. The female participants are more of Slight Tagasalo while the male participants are dominant as Absolute Tagasalo. In regard to birth order and gender, the majority of the participants are Slight Tagasalo. Eventually, the findings in this study are still conclusive; on the contrary, the intervention of the non-probability sampling method may threaten the generalizability of the findings and the representation of the entire population (Saunder, et al, 2009; Hakan, 2013; \& Andridge, et al., 2019).

\section{Limitations and Future Directions}

There are various limitations found in the present study. However, these limitations are reasonable and abrupt. In this study, there were only 27 participants who responded during the conduct of the data gathering, and this small sample size was selected through non-probability sampling such as purposive and convenience sampling techniques. Bengart et al. (2017) mentioned that the success of research depends on the appropriateness of the sampling method being utilized, and the appropriateness of the sampling method may influence the sample characteristics and the generalizability of the results. Hakan (2013) had proven that a sample size of 30 does not provide an adequately unbiased estimation of the generalizability coefficient for relative evaluation and the index of dependability for absolute decision. The limitation of the sample as well as the sampling technique in this study was due to community quarantine (Omnibus Guidelines on the Implementation of Community Quarantine in the Philippines, 2021) hindered the researcher from generating the ideal sample and to employ probability sampling. Hence, results in this study were still conclusive, which on the other hand, the intervention of the non-probability sampling method may threaten the generalizability of the research findings and the representation of the entire population (Saunders, et al. 2009, pp. 233-241). Similarly, non-probability samples were susceptible to biased descriptive estimates (Andridge, et al., 2019).

In this study, the constructed personality scale was employed to determine the tagasalo personality, and this scale consists of 35 items that describe the tagasalo as Absolute Tagasalo, Slight Tagasalo, Potential Tagasalo, and the Non-Tagasalo. A tagasalo (catcher), as described by Carandang (1987), was an eldest female Filipino or, in her absence, the middle-born child who took a household role and eventually shifted to emotional care to the members of the family. Moreover, the tagasalo in this study was not particular to a firstborn or middle-born female child, and the study was not intended to affirm or disprove the theory of tagasalo. This limitation rather generated new concepts of the tagasalo who is not specific to gender and birth order, and to a certain extent, it affirmed the findings of Udarbe (2001), who brought to light that the tagasalo was not confined to the female eldest child. However, in connection to gender, the study overlooked determining the tagasalo personality in regard to sexual orientation. Kowalski and Scheitle (2019) found that both gay men and lesbian women, when it comes to household and family roles, they were more likely than their heterosexual peers who reject traditional gender roles. Kulik (2018) confirmed that egalitarianism in gender-role attitudes was comparable among homosexuals and heterosexuals as well as among men and women. Komlenic, et al. (2020) found that femininity, masculinity, and communication were significant predictors of positive attitudes towards life in both men and women. In addition, Giola and Kajonus (2019) confirmed that country's sex differences were strongly correlated with their Gender-Equality Index, and as gender equality increases, both men and women tend to gravitate towards their traditional gender roles. Hence, these findings are interesting researches that can be associated with tagasalo personality.

Age is one of the variables which was not tackled in this study. Finn, et al. (2018) found that age was not significantly correlated to personality specific to Big Five personality development. However, they suggested that age differences should be considered even in specific life stages to augment the understanding of personality development. In the tagasalo personality scale, the items such as $3,7,10,16,21,26$, and 35 are the indicators of the tagasalo personality which occur in the early stage of life. Likewise, the items served as determinants of the early development of the tagasalo personality. However, in this study, age was not considered as one of the variables that can 
International Journal of Entrepreneurship, Business and Creative Economy (IJEBCE), Vol. 2 (1), 48-66 Exploring the Tagasalo Personality and Its Implication as a Localized Personality Scale

Arnel G. Perez

be correlated in determining the early occurrence of tagasalo personality. Similarly, the items mentioned were not analyzed to determine the early development of tagasalo personality among the participants. Hence, for future research, age should be considered as one of the exogenous variables in exploring the tagasalo personality.

\section{ACKNOWLEDGMENT}

The author would like to acknowledge the following staff, faculty, field of the study heads, and deans of the institutes who voluntarily participated in this study.

\section{REFERENCES}

Adiputra, S., Syahril, Y., \& Syamsu, I. (2020). The Effect of parenting patterns and empathy behavior on youth prosocial. International Journal of Instruction, Vol.13(3), pp. 2223-232. https://eric.ed.gov/?id=EJ1259370

Adler, A. (1927). Understanding Human Nature. https://archive.org/details/in.ernet.dli.2015.126777/page/n111/mode/1up?q=Firstborn

Agor, R.M., Cabahug, H.J.P., Dungca, J.M.M., Fugueroa, B.P., Patricio, L.A.G., \& roxas, M.D.C. (2018). A correlation study between parentification and memory retention among parentified female adolescent: A Neurocognitive perspective of parentification.

https://www.researchgate.net/publication/343775176_A_Correlational_Study_between_Pa rentification

_and_Memory_Retention_among_Parentified_Female_Adolescents_A_Neurocognitive_Perspective_ on_Par entification/link/5f4108d092851cd30215e0fa/download

Aldhafri, S.S., Alrajhi, M.N., Alkharusi, H.A., Al-Harthy, I.S., Al-Barashdi, H.S. \& Alhdabi, A.S. (2020). Parenting styles and academic self-efficacy beliefs of Omani School and University Students. Education Sciences, Vol.10, Article 229. https://eric.ed.gov/?id=EJ1272205

Andridge, R.R., Boonstra, P.S., Alvarado-Leiton, F., Little, R.J., \& West, B.T. (2019). Indices of nonignorable selection bias for proportions estimated from non-probability samples. Journal of the Royal Statistical Society, Vol. 68, pp. 1465-1483.

http://web.b.ebscohost.com/ehost/pdfviewer/pdfviewer?vid=3\&sid=9e548033-c567-46869e3b-1901370204d0\%40pdc-v-sessmgr05

Atenas, P., Bobis, C.F., Maghanoy, C.J., Manondo, M., Perez, G.M., \& Tucay, L. (2018). Ang Pagsalo: A parentification study among female adolescents.

https://www.academia.edu/38423411/Ang_Pagsalo_A_Parentification_Study_Among_Femal e_Adolesce nts_pdf

Barclay, K., Hallstern, M., \& Myrskyla, M. (2017). Birth order and college major in Sweden. Social Forces, Vol. 96(2), p. 629-660.

http://web.a.ebscohost.com/ehost/pdfviewer/pdfviewer?vid=5\&sid=4776aca4-1fca-4dc1-b7d9c5b1872dd13f\%40sessionmgr4007

Bengart, P., Lehmann, S., Sarstedt, M., \& Shaltoni, A. (2017). The use of sampling methods in advertising research: a gap between theory and practice. International Journal of Advertising, Vol. 37(4), p. 650-663. https://doi.org/10.1080/02650487.2017.1348329

Blazevic, I. (2016). Family, peer and school influence on children's social development. World Journal of Education. https://www.researchgate.net/publication/299499258

Capuno, J., Mendonza, A., \& Morillo, H. (2013). Views and values on family among Filipinos: An 
International Journal of Entrepreneurship, Business and Creative Economy (IJEBCE), Vol. 2 (1), 48-66 Exploring the Tagasalo Personality and Its Implication as a Localized Personality Scale

Arnel G. Perez

empirical exploration. (Abstract) Asian Journal of Social Science, Vol.41(1), p.5-28. https://doi.org/10.1163/156853314-12341278

Carandang, M.L.A. (1987). Filipino children under stress: Family dynamics and therapy. Quezon City: Ateneo de Manila University Press.

Coan, A., Garcia, K.D., \& Sabuncu, P. (2018). Birth order theory and habit formation: a literature review. http://web.a.ebscohost.com/ehost/pdfviewer/pdfviewer?vid=3\&sid=4776aca41fca-4dc1- b7d9-c5b1872dd13f\%40sessionmgr4007

Giola, E.M. \& Kajonus, P.J. (2019). Sex differences in personality are larger in gender equal countries:

Replicating and extending a surprising finding. International Journal of Psychology, Vol. 54(6), pp.705-711. http:// web.a.ebscohost.com/ehost/pdfviewer/pdfviewer?vid=2\&sid=8918a4249bdc-4c52- bc7d-9812db69c477\%40sessionmgr4007

Finn, C., Hagemeyer, B., Mund, M. \& Push, S. (2018). Personality development in emerging and young adulthood. A study of age differences. European Journal of Personality, Vol.33, pp.245263. http://web.a.ebscohost.com/ehost/pdfviewer/pdfviewer?vid=10\&sid=8918a4249bdc-4c52-bc7d- 9812db69c477\%40sessionmgr4007

Hakan, A. (2013). Sample size for estimation of G and Phi coefficients in generalizability theory. Eurasian Journal of Educational Research, n51, pp.215-227. https://eric.ed.gov/?id=EJ1059904

Jalajas, D., \& Tricarichi-Funk, C. (2018). The effect of birth order on personality and leadership. http://web.a.ebscohost.com/ehost/pdfviewer/pdfviewer?vid=8\&sid=4776aca4-1fca-4dc1b7d9- c5b1872dd13f\%40sessionmgr4007

Kosterelioglu, I. (2018). Effect of Parenting styles on students' achievement goal orientation: A Study on high school students. Educational Policy Analysis and Strategic Research, Vol.13(4), pp.91-107. https://eric.ed.gov/?id=EJ1201485

Kowalski, B.M., \& Scheitle, C.P. (2019). Sexual identity and attitudes about gender roles. Sexuality and Culture,Vol. 24, pp. 671-691.

web.b.ebscohost.com/ehost/pdfviewer/pdfviewer?vid=6\&sid=f65a7369-ddca-41dc-bd75f1da5654b1fb\%40pdc-v-sessmgr01

Komlenic, M., Snele, M.S., \& Todovoric, J. (2020). Gender roles and dimension of family functioning as predictors of subjective well-being in men and women. TEME,Vol.44 (3), pp. 681-701. http://web.a.ebscohost.com/ehost/pdfviewer/pdfviewer?vid=36\&sid=4776aca4-1fca-4dc1b7d9- c5b1872dd13f\%40sessionmgr4007

Kulik, L. (2018). Explaining egalitarianism in gender-role attitudes: The Impact of sex, sexual orientation, and background variables. Asia Women, Vol. 34 (2), pp. 61-87. http://web.a.ebscohost.com/ehost/pdfviewer/pdfviewer?vid=6\&sid=f845d10e-cad9 4174b414-ffb0f29f1b64\%40sessionmgr4006

Lawrence, E., \& Mollborn, S. (2018). Family, peer, and school influences on children's developing health lifestyle. Journal of Heakth and Social Behavior, Vol.59(1), pp. 133-150. https://journals.sagepub.com/doi/full/10.1177/0022146517750637

Miller, A.L. \& Speirs Neumeister, K.L. (2017). The influence of personality, parenting styles, and perfectionism on performance goal orientation in high ability students. Journal of Advanced Academics, Vol. 28(4), pp. 313-344.

http://web.a.ebscohost.com/ehost/pdfviewer/pdfviewer?vid=10\&sid=68f117f8-f0b7-4be0a3c1- 835a2724fcbe\%40sessionmgr4007 
International Journal of Entrepreneurship, Business and Creative Economy (IJEBCE), Vol. 2 (1), 48-66 Exploring the Tagasalo Personality and Its Implication as a Localized Personality Scale

Arnel G. Perez

Omnibus Guidelines on the Implementation of Community Quarantine in the Philippines with Amendments as of January 21, 2021.

https://www.officialgazette.gov.ph/downloads/2021/01jan/20210121-IATF-OMNIBUSGUIDELINES- RRD.pdf

Saunders, M., Lewis, P. \& Thornhill, A. (2009). Research Methods for Business Students 5th edition, Pearson Education Limited, pp. 233-241.

https://www.academia.edu/23374295/Research_Methods_for_Business_Students_5th_Editi on

Tuazon, A.D. \& Quinain, K.T. (2020). Developing a scale to measure tagasalo personality. PAP Regional Research E-Conference. https://www.youtube.com/watch?v=TcjH74M5-I8

Udarbe, M. H. (2001). The Tagasalo Personality. Philippine Journal of Psychology, Vol. 34(2), p. 4565. https://pssc.org.ph/wp-

content/psscarchives/Philippine\%20Journal\%20of\%20Psychology/2001/Num\%202/06_T he\%20Tagasalo\%20Per sonality.pdf

\section{Software Application}

Microsoft Excel for $\quad$ Mac software version $16.40 \quad$ (2019). Microsoft Corporation.

https://support.office.com/legal?llcc=enus\&aid=Office_Mac_Use_Terms_2018_en-us.htm 